Vol.02/ No. 02

Pages: 73-90

https://www.irojournals.com/itdw/

DOI: https://doi.org/10.36548/jitdw.2020.2.001

\title{
Developing Domain Ontology for Issuing Certificate of Citizenship of Nepal
}

\author{
Rama Bastola, \\ Nepal Open University, Lalitpur, Nepal \\ Email:rbastola@tcioe.edu.np \\ SubarnaShakya \\ Pulchowk Campus, Institute of Engineering, Tribhuwan University, Lalitpur, Nepal \\ Email:drss@ioe.edu.np
}

\begin{abstract}
Most of the existing software systems are web-based and interactive. Semantic Web Technologies further allows for organizing and encoding information meaningfully. It enables software agents to interpret the information. However, the representation of information in different format has made challenging to interoperate among the heterogeneous systems. The representation of heterogeneous system with common standards and vocabularies is an effective solution for interoperability. For this, development of domain ontology is required for common understanding of the concept. The research work is mainly focused on development of domain ontology for issuing Citizenship of Nepal as e-government is widely considered as a good example of heterogeneous system. Protégé is used as ontology editor and Web Ontology Language (OWL) is used for representation of the concepts. A hybrid methodology with Unified Modelling Language (UML) is used to get in-depth concept of the domain. The domain ontology is verified using built-in reasoner of Protégé and validated with answering competency questions of the domain using SPARQL query.
\end{abstract}

Keywords: Certificate of Citizenship, Domain Ontology, OWL, Protégé, SPARQL, Unified Modelling Language

\section{Introduction}

Web technologies play vital role in converting the developed world toward a knowledge society [1] whereas Semantic web technologies allows organizing and encoding information meaningfully creating advanced knowledge management system. It enables effective communication between machine to machine as well as machine to human and vice-versa.

Most of the today's systems are interactive and heterogeneous in nature for example e-Government systems, Internet of Things (IoT), Health-care systems. It is more challenging to make the heterogeneous system interoperable due to representation of information in different format.The representation of heterogeneous system with common standards and vocabularies using Web 
Journal of Information Technology and Digital World (2020)

Vol.02/ No. 02

Pages: $73-90$

https://www.irojournals.com/itdw/

DOI: https://doi.org/10.36548/jitdw.2020.2.001

Ontology Language (OWL) are found to be effective solutions for interoperability and also used in interoperability benchmarking [2]. E-government system can be taken as a good example of heterogeneous system hence the research project is focused on developing domain ontology using OWL for issuing Certificate of Citizenship of Nepal.

\subsection{Background Introduction}

An ontology defines a common vocabulary with a set of concepts and categories showing the properties of particular subject area and relationship between them. Domain ontology describes the vocabulary related to a particular domain and are machine-interpretable. Domain ontology models domain specific terms to separate domain knowledge from the operational knowledge and to analyze the domain knowledge [3]. It improves the interoperability and knowledge sharing problems with common understanding of concepts hence increases the research interest in the area of domain ontology.

OWL is a semantic markup language recommended by World Wide Web Consortium (W3C) to encode the knowledge of Semantic Web[4]. OWL consists of three types of entities such as classes, properties and individuals which can be represented in Description Logic (DL). It is more expressive language and designed to represent rich and complex knowledge about hierarchies of things and relations between things.

The field of e-government is broad and can be defined as the use of ICT to unify the services of government agencies into a portal. Most of the countries are providing e-government services to their citizen [5]. Most of the countries have released their e-government strategies and approaches which are evaluated by United Nations survey in every alternate year. It shows significant progress in all aspects of public administrations but it is not satisfactory. Many difficulties arises in e-government efforts due to lack of interoperability and integration of system [6].

\subsection{Problem Statement}

In Nepal, few e-government services have been implemented and it is prioritized in Digital Nepal Framework to provide better services to its stakeholders. National identity of Nepalese people is Certificate of Citizenship which has to be submitted for most of the official work such as application 
Journal of Information Technology and Digital World (2020)

Vol.02/ No. 02

Pages: $73-90$

https://www.irojournals.com/itdw/

DOI: https://doi.org/10.36548/jitdw.2020.2.001

of Driving license, Company Registration, Bank Account Opening. In most of the official work, applicant has to submit his/her three generation information along with general information which has already submitted to District Administration Office while obtaining certificate of citizenship. It increases data redundancy, inconsistency and inefficiency in terms of time and space complexity too. The heterogeneous representation of data has become key problem in seamless integration and interoperability among the underlying services.

\subsection{Objectives}

Ontology has been considered as a standard and formal representation of knowledge in information systems, engineering discipline and computer science. Representation of concepts used in issuing certificate of citizenship in domain ontology can be good solution for interoperability of different egovernment services. The main objectives of the research project are: to build domain ontology for issuing certificate of citizenship and to evaluate consistency of the citizenship ontology

\subsection{Scope and Limitations}

The research project focuses on the development and evaluation of domain ontology for concepts used in Acquisition of Nepali Citizenship by Descent and Acquisition of Nepali Citizenship by Birth as per the Nepal Citizenship Act 2006 and Nepal Citizenship Rules 2006.

Several provisions for acquisition, revocation and reapplication for certification of citizenship are defined in the Nepal Citizenship ACT and Rules but this work only focuses on conceptualization of terms used in issuing certificate of citizenship by decent and by birth.

\section{Related Works}

The related works arestudiedin two sections. The first section focuses on the process of ontology development and the second section analyses the related work in domain ontology focusing on citizenship ontology. 
Journal of Information Technology and Digital World (2020)

Vol.02/ No. 02

Pages: 73-90

https://www.irojournals.com/itdw/

DOI: https://doi.org/10.36548/jitdw.2020.2.001

\subsection{Ontology Development Methodologies}

Several methodologies for development of ontology are studied and it is found that there is no standard method for development of ontology. Uschold and King [7] methodology is taken as reference methodology in several research work in ontology development. In the work, very general issue of categorization in modeling is considered first which is related to the process of ontology capture. Then, it describes the procedure to identify the terms and produce definition with proper handling of ambiguous terms. It also suggests that defining terms which are 'cognitively basic' first can lead to less re-work. In Ontology Development 101 guide [3], ontology development methodology for declarative frame-based systems is described. It listed step by steps ontology development process which is easy to understandable by beginners too. The guide addressed the complex issues of defining class hierarchies, object properties and instances of classes. The authors also mentioned that "there is no single correct ontology for any domain". Ontology developed by different experts may be different for the same domain.

A hybrid methodology is purposed in the research work[8] where software and ontology engineering are considered as two complimentary branches. It suggests a hybrid methodology for development of ontology from existing matured software engineering. The methodology used UML based modeling approaches to bridge the gap between the engineering branches and derived as a hybrid of linear model of waterfall and iterative Rational Unified Process. In this research work, hybrid approach implementing above discussed methodologies is followed which are also used by several ontology development research work successfully such as [9],[10].

\subsection{Existing e-Government Domain Ontologies}

Domain ontology has been developed by academic and industrial researchers in various domain. In the research work[9], a systematic approach is used to define a Domain Ontology for a Budgetary and Financial System which could be extended by Task Ontologies for further use by different government applications. The research paper[11] presented a knowledge base modelling approach for e-Government domains using ontologies, semantic web and semantic web services. It is based on set of ontologies domain, legal, service and SitCtx. Here, authors have focused on application of the domain ontology in public administration services and could not found evaluation of consistency of the domain ontology. In the research work [12], top level domain ontology for e-Government is 
Journal of Information Technology and Digital World (2020)

Vol.02/ No. 02

Pages: $73-90$

https://www.irojournals.com/itdw/

DOI: https://doi.org/10.36548/jitdw.2020.2.001

presented with four dimensions namely left to right, Medium, Entity, Service and Outcome. The work focus on local/municipal e-Governments perspective only. However, the work can be used to develop a roadmap for e-Government.

In the article [13], several farming dataset of Nepal are converted into RDF which increases the data re-usage and integration. It describes the conversion, linking, and publication process with use cases. It provides the AgriNepalData data sources as Linked Data and combines them with other datasets. As a result, it is possible to obtain a variety of related agricultural information from one structured dataset. With searching and analysis of several literatures in the field of domain ontology, it is found that domain ontology for e-Government services of Nepal has not been developed yet.

The work on [13] focuses on agriculture domain of Nepal. Since domain ontology is foundation for knowledge management and sharing in semantic web services, the need of development of domainotology for e-Government System is realized. In this research work, development and evaluation of domain ontology for issuing citizenship of Nepal is attempted.

\section{Proposed Work}

\subsection{Generic Model of the Ontology Development}

This research work used the hybrid approach which is mostly derived from [9] since the methodology is considered as the most mature while comparing with the IEEE standard [10]. The methodology is also influenced by the 101 guide as described in [3].

The methodology consists of specification, conceptualization and implementation phases. The specification is the knowledge gain phase which describes the domain and defines ontology goal and scope. The conceptualization is the knowledge organizing and structuring phase which enumerates important terminologies, identifies classes and its hierarchy, define relations and attributes. This phase uses external representations for the knowledge representation. The implementation is the final phase which builds the ontology using some technological environment. 
Journal of Information Technology and Digital World (2020)

Vol.02/ No. 02

Pages: 73-90

https://www.irojournals.com/itdw/

DOI: https://doi.org/10.36548/jitdw.2020.2.001

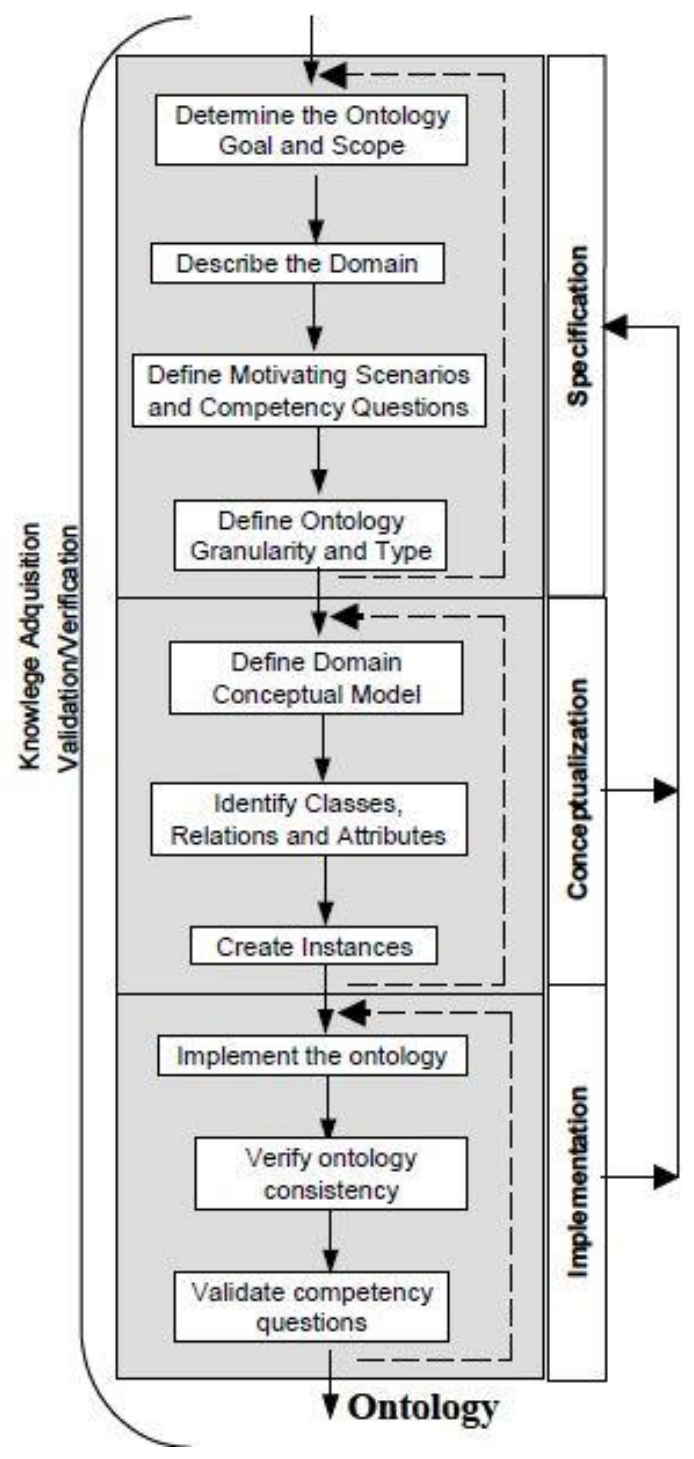

Figure 1: A Domain Ontology Development Process [9]

\subsection{Specification Phase}

The specification phase consists of four major tasks which are: Determining Ontology Goal and Scope; Describing the Domain; Defining Competency Questions; and Defining Ontology Granularity. The goal of ontology is determined to be used for issuing certificate of citizenship of Nepal. The scope of the ontology includes the concepts for the certificate by descent and certificate by birth. As per the 
Journal of Information Technology and Digital World (2020)

Vol.02/ No. 02

Pages: $73-90$

https://www.irojournals.com/itdw/

DOI: https://doi.org/10.36548/jitdw.2020.2.001

methodology described in Ontology Development 101[3], important terms of the domain of interest are to be enumerated, described and analyzed to obtain the domain knowledge. In this analysis, Nepal Citizenship Act 2006 [14] and Nepal Citizenship Rules 2006 [15]were studied. A procedure for Obtaining Certificate of Citizenship of Nepal by Descent is described by the flowchart as shown in figure 2 .

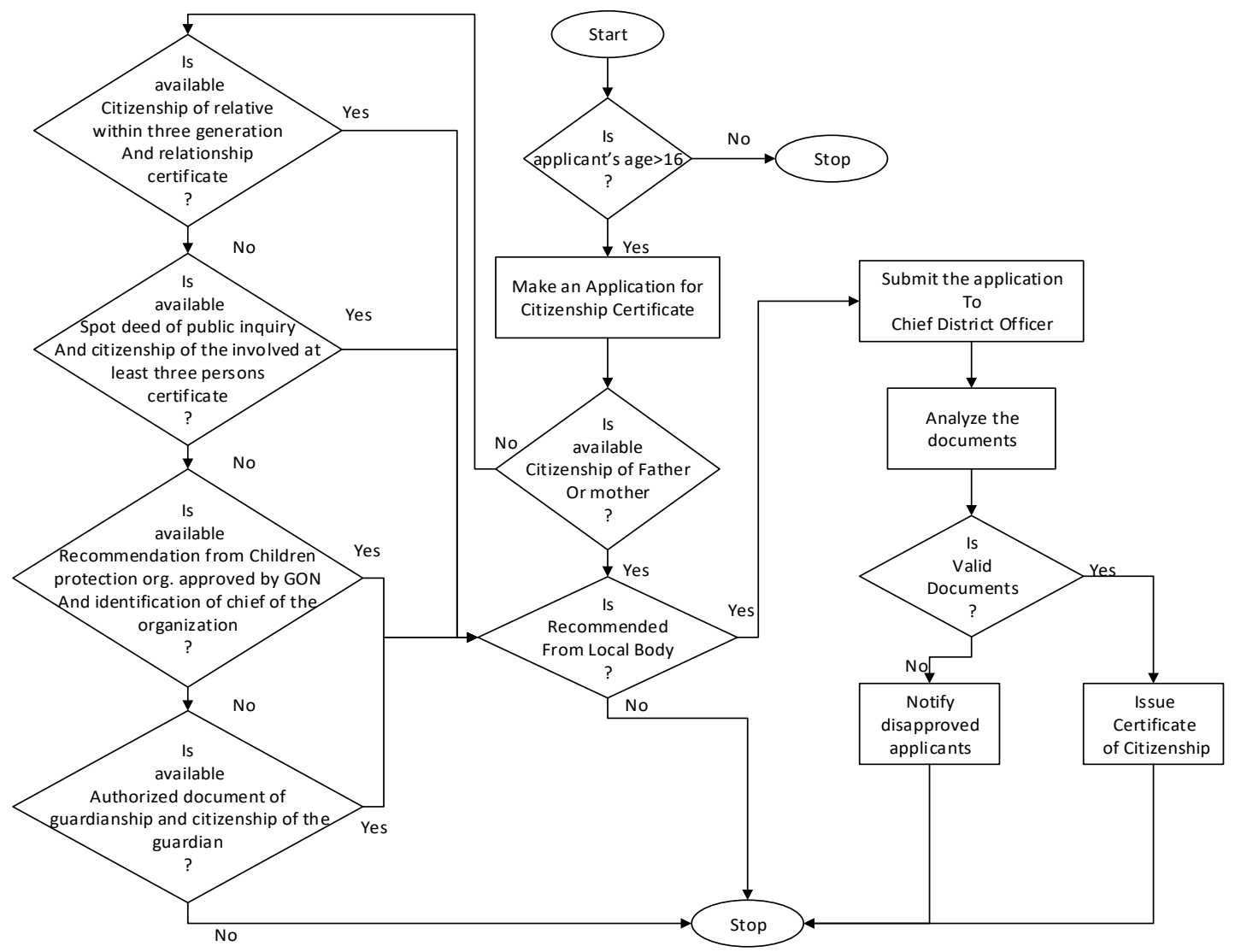

Figure 2: Procedures for Obtaining Certificate of Citizenship of Nepal by Descent

Defining competency questions determines scope of the ontology and is used in validation of the ontology by checking whether it could answer the competency questions using its own terms, axioms and definitions [9]. Some of the competency questions for general concepts of issuing certificate of citizenship are shown in table 1.

Table 1: A subset of Competency Questions

\begin{tabular}{|l|l|}
\hline S.n. & Competency Questions \\
\hline 1 & What is the age requirement of an applicant? \\
\hline 2 & To whom does applicant submit the application for obtaining citizenship? \\
\hline 3 & Who is responsible for issuing letter of recommendation? \\
\hline
\end{tabular}


Journal of Information Technology and Digital World (2020)

Vol.02/ No. 02

Pages: $73-90$

https://www.irojournals.com/itdw/

DOI: https://doi.org/10.36548/jitdw.2020.2.001

\begin{tabular}{|l|l|}
\hline 4 & What are the requirements to obtain citizenship by descent? \\
\hline 5 & What are the requirements to obtain citizenship by birth? \\
\hline 6 & How many local persons involve in identification of the applicant in spot deed \\
\hline 7 & How many persons involve in conduction of spot deed public inquiry? \\
\hline 8 & Who is responsible for issuing the certificate of citizenship? \\
\hline 9 & List Name, Address, and Date of birth of all applicants (by Descent and by Birth) \\
\hline 10 & $\begin{array}{l}\text { List out the detail information along with submitted documents submitted by } \\
\text { applicant by descent }\end{array}$ \\
\hline
\end{tabular}

There are different granularity of ontology such as upper ontologies, middle ontologies, domain ontologies and application ontologies[10]. This research work focuses on the domain ontologies related to citizenship domain which describes knowledge related to procedures for obtaining certificate of citizenship by descent and by birth.

\subsection{Conceptualization Phase}

The conceptualization phase consists of three main tasks which include Defining Domain Conceptual Model; Identifying Classes, Relations and attributes; and Creating Instances. A domain conceptual model can be viewed as a representation of real-world conceptual classes which is not of software components but it clearly defines requirements of the software. Using Unified Modeling Language (UML)[16] notations, a domain model is demonstrated with a set of class diagram in which no operations are defined. The three components of the domain model are domain objects or conceptual class, associations between

\begin{tabular}{|c|c|c|c|}
\hline Applicant & $\begin{array}{c}\text { Local } \\
\text { Body }\end{array}$ & $\begin{array}{c}\text { Certificate of } \\
\text { Citizenship }\end{array}$ & $\begin{array}{c}\text { Spot-Deed of } \\
\text { Public }\end{array}$ \\
\hline Father & Mother & Guardian & $\begin{array}{c}\text { Local } \\
\text { Inhabitant }\end{array}$ \\
\hline $\begin{array}{c}\text { Citizenship } \\
\text { ByDescent }\end{array}$ & $\begin{array}{c}\text { Citizenship } \\
\text { ByBirth }\end{array}$ & $\begin{array}{c}\text { LocalBody } \\
\text { Representative }\end{array}$ & $\begin{array}{c}\text { Birth } \\
\text { Identification }\end{array}$ \\
\hline $\begin{array}{c}\text { Application } \\
\text { for }\end{array}$ & $\begin{array}{c}\text { Chief } \\
\text { District }\end{array}$ & $\begin{array}{c}\text { Child } \\
\text { Organization }\end{array}$ & $\begin{array}{c}\text { Police } \\
\text { Report }\end{array}$ \\
\hline
\end{tabular}

Table 2: A Subset of Kev Terms

ISSN: 2582-418X (online)

Information Technology 
Journal of Information Technology and Digital World (2020)

Vol.02/ No. 02

Pages: $73-90$

https://www.irojournals.com/itdw/

DOI: https://doi.org/10.36548/jitdw.2020.2.001

conceptual classes and attributes of the conceptual classes. Some of the key terms are shown in table 2.

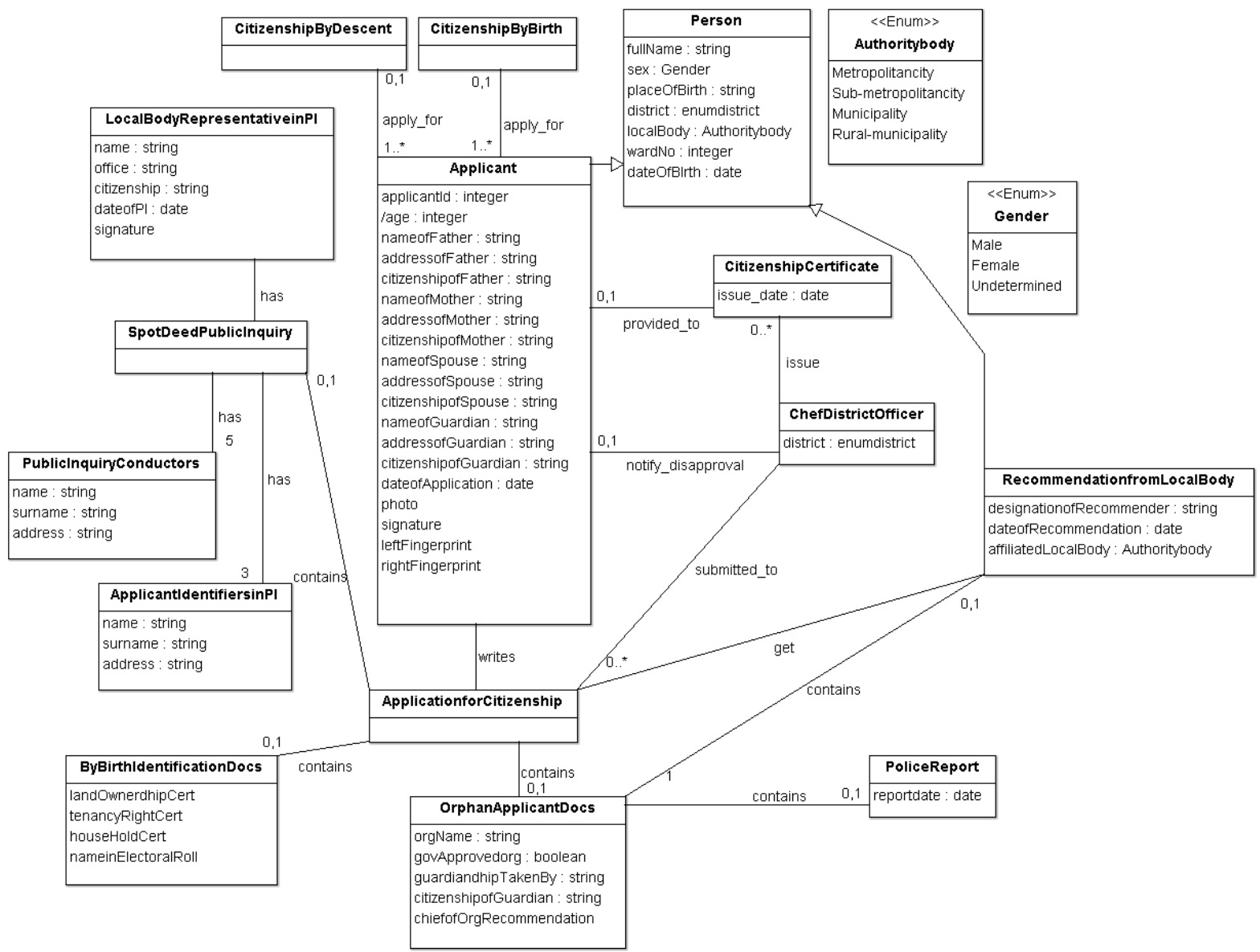

Figure 3:A Domain Model in UML

After identification of the key terminologies of the domain, conceptual classes, relationships among the classes and required attributes are identified. These concepts are illustrated with the UML domain model as shown in Figure 3. Then, relevant instances of the domain are defined and tabulated. The instances table consists of the instance name, the concept if belongs to, the attributes or properties and attribute's value[10] if available. The following table 3 shows an excerpt of the Instance Table of the Citizenship Ontology.

Table 3:An excerpt of the Instances of the Citizenship Ontology

\begin{tabular}{|l|l|l|l|}
\hline Concept Name & Instance & Attributes & Value \\
\hline ApplicantByDescent & Applicant- & fullName & Aaron Neupane \\
\cline { 3 - 4 } & & Address & Chitwan \\
\hline
\end{tabular}


Journal of Information Technology and Digital World (2020)

Vol.02/ No. 02

Pages: $73-90$

https://www.irojournals.com/itdw/

DOI: https://doi.org/10.36548/jitdw.2020.2.001

\begin{tabular}{|l|l|l|l|}
\hline \multirow{2}{*}{1} & dateOfBirth & $01 / 01 / 2002$ \\
\cline { 3 - 4 } & dateOfApplication & $04 / 11 / 2020$ \\
\cline { 3 - 4 } & ageAtApplicationDay & 17 \\
\cline { 3 - 4 } & has Application & Application for Certificate \\
\cline { 3 - 4 } & hasDocument & RecommendationforCitizenship \\
\cline { 2 - 3 } & hasFather & Krishna Neupane \\
\cline { 3 - 4 } & hasMother & KripaNeupane \\
\hline
\end{tabular}

\subsection{Implementation Phase}

Domain ontology for citizenship is represented in Web Ontology Language (OWL) [4] using Protégé[17] editor. Protégé is the open source editor with extensible features for rapid prototyping and verifying the ontology with reasoners. Protégé is flexible which supports various plugins. SPARQL (SPARQL Protocol and RDF Query Language) is used to query the ontology for its validation. OWL is used to represent the ontology because of its expressiveness and powerful knowledge representations. Citizenship Ontology is developed in Protégé 5.5 editor. A snapshot of Citizenship class hierarchyis shown in figure4.Similarly, object properties hierarchy, data hierarchy and instances are creates in the protégé. 
Journal of Information Technology and Digital World (2020)

Vol.02/ No. 02

Pages: $73-90$

https://www.irojournals.com/itdw/

DOI: https://doi.org/10.36548/jitdw.2020.2.001

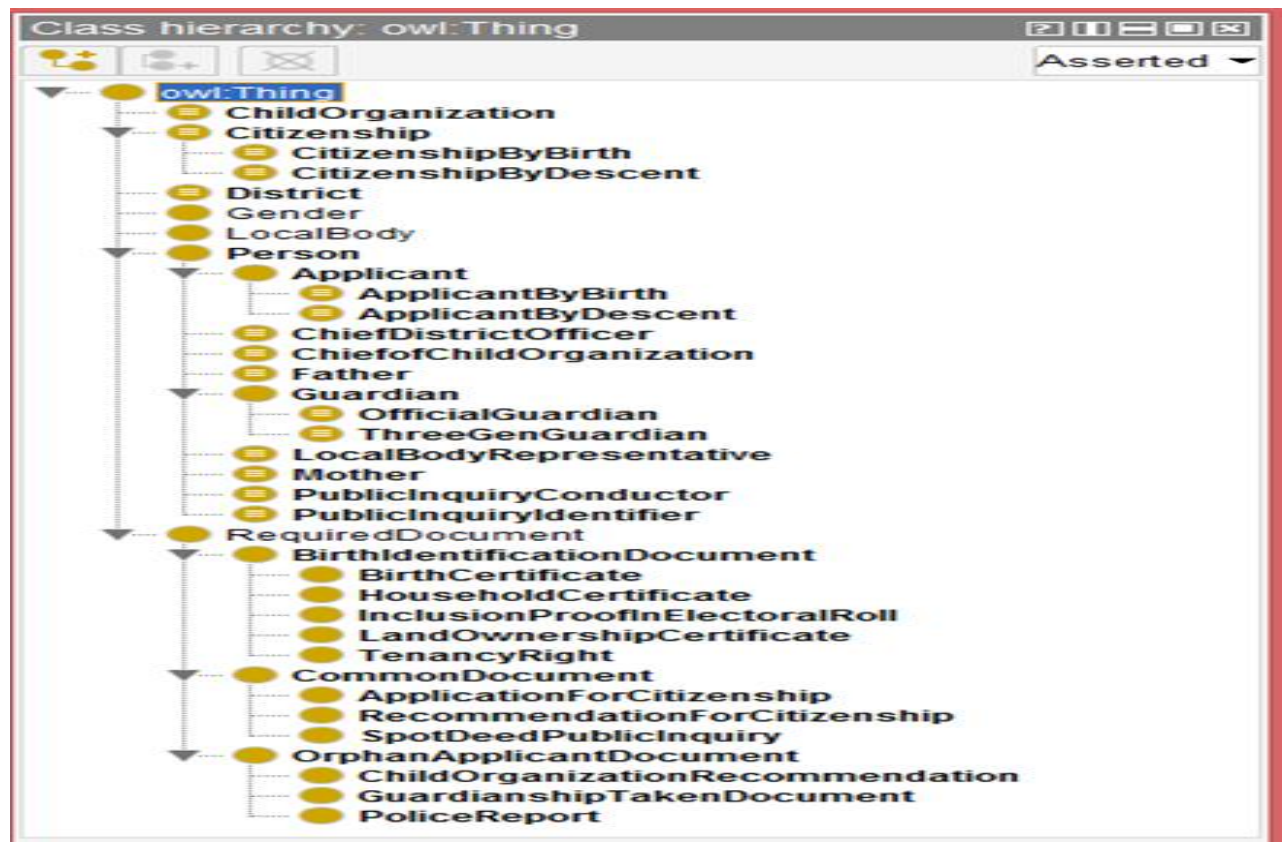

Figure 4: A snapshop of Citizenship Ontology Entities in Protégé Editor

\section{RESULT AND DISCUSSION}

\subsection{Result Analysis using Reasoner}

The developed Citizenship ontology metrics contains 269 declared axioms which are distributed among 36 classes, 27 object properties, 7 data properties and 33 individual counts. The ontology is verified using Protégé build-in reasoned HermiT. The reasoner is used to test whether or not one class is a subclass of another class. The reasoned computes the inferred ontology class hierarchy by performing such tests on the classes[17]. The generated inferred ontology class hierarchy is shown in the figure 5 .

The reasoner has another standard service for checking consistency. The consistency can be verified by checking whether it is possible for the class to create any instances or not [17]. A class is said to be inconsistent if its instances cannot be created. In this work, 33 individuals are created which verifies that the ontology is consistent. 
Journal of Information Technology and Digital World (2020)

Vol.02/ No. 02

Pages: $73-90$

https://www.irojournals.com/itdw/

DOI: https://doi.org/10.36548/jitdw.2020.2.001

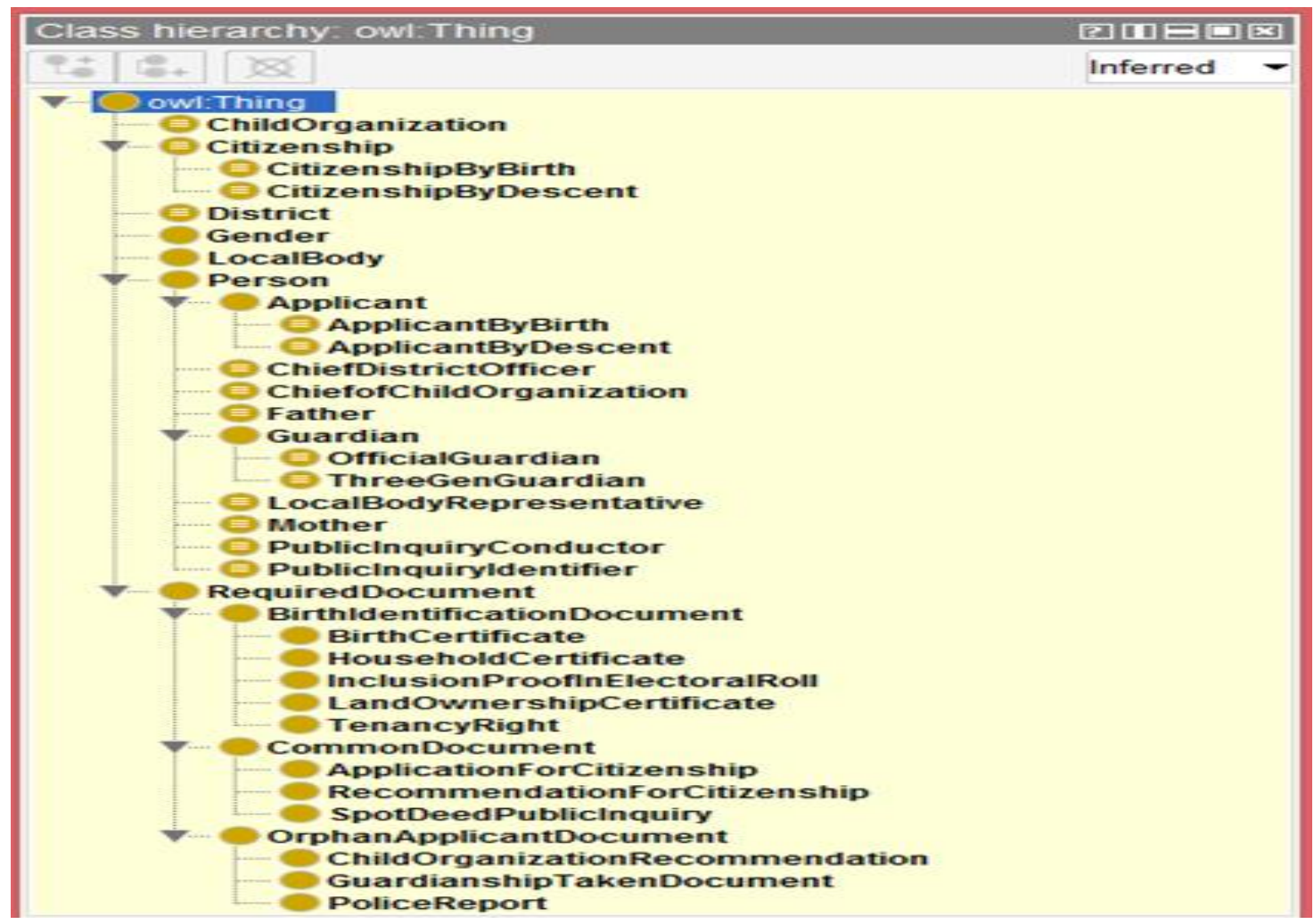

Figure 5: Inferred Class Hierarcy

Generated by HermiT Reasoner in Protégé

\subsection{Result Analysis using Ontology Querying}

SPARQL query is used to validate the ontology by answering the competency questions as defined in section 3.2. The similar approach is used in validating the domain ontology by most of the research works [9][10].Some of the results are shown here. Competency Question 3:Who is responsible for issuing letter of recommendation?: The result of the SPARQL query of figure 6 shows that LocalBodyRepresentative is responsible for issuing letter of recommendation for issuing citizenship.

Competency Question 9: List Name, Address, and Date of birth of all applicants (by Descent and by Birth): The SPARQL query result shows union of the applicants who applied for citizenship by birth and citizenship by descent. It shows applicants details such as fullname, address and date of birth. 
Journal of Information Technology and Digital World (2020)

Vol.02/ No. 02

Pages: $73-90$

https://www.irojournals.com/itdw/

DOI: https://doi.org/10.36548/jitdw.2020.2.001

The result shows that all of the competency questions could be answered using SPARQL query. Hence, the developed domain ontology is a valid ontology for citizenship domain of Nepal.

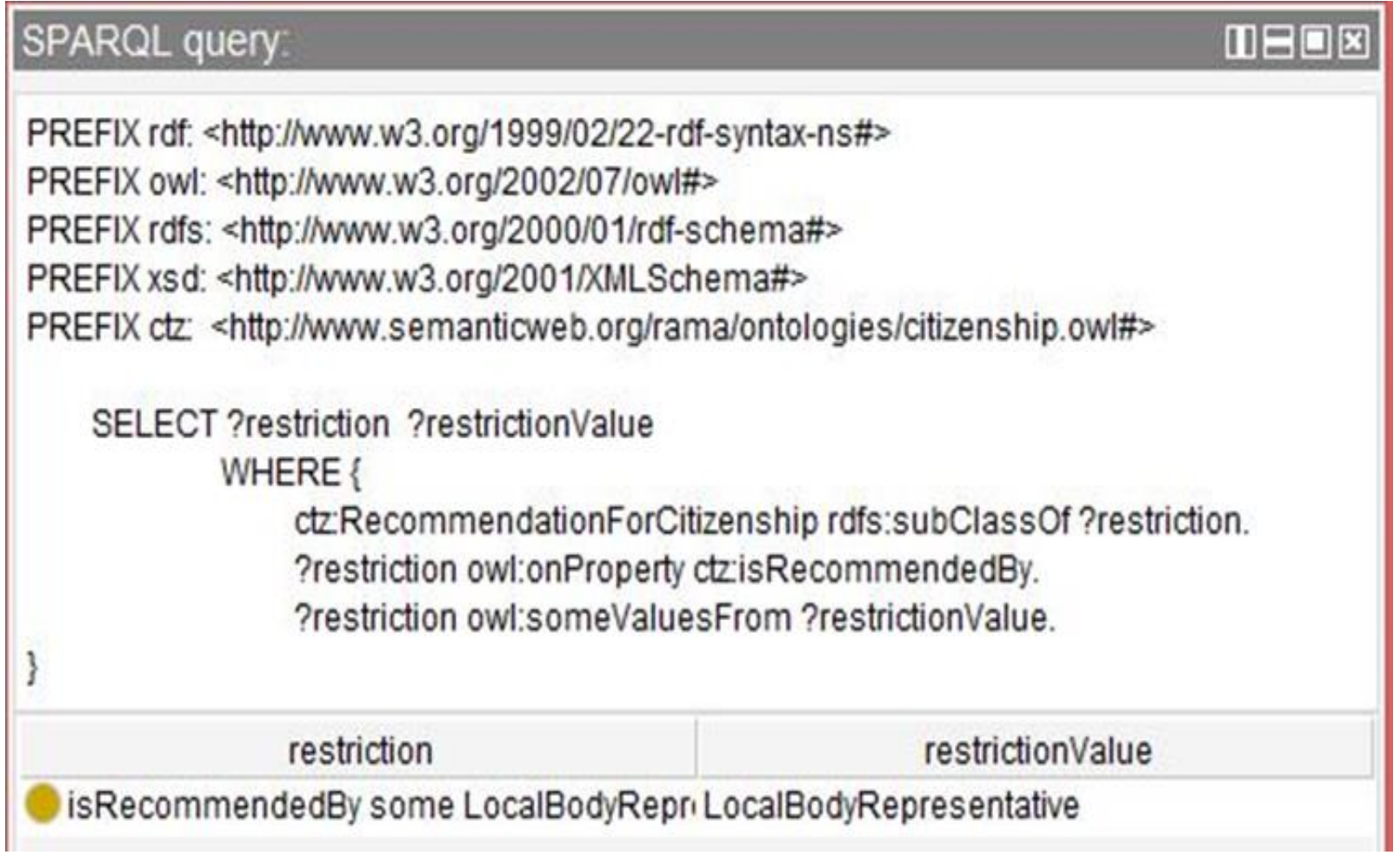

Figure 6: SPARQL Query and Result for Competency Question 3 
Journal of Information Technology and Digital World (2020)

Vol.02/ No. 02

Pages: $73-90$

https://www.irojournals.com/itdw/

DOI: https://doi.org/10.36548/jitdw.2020.2.001

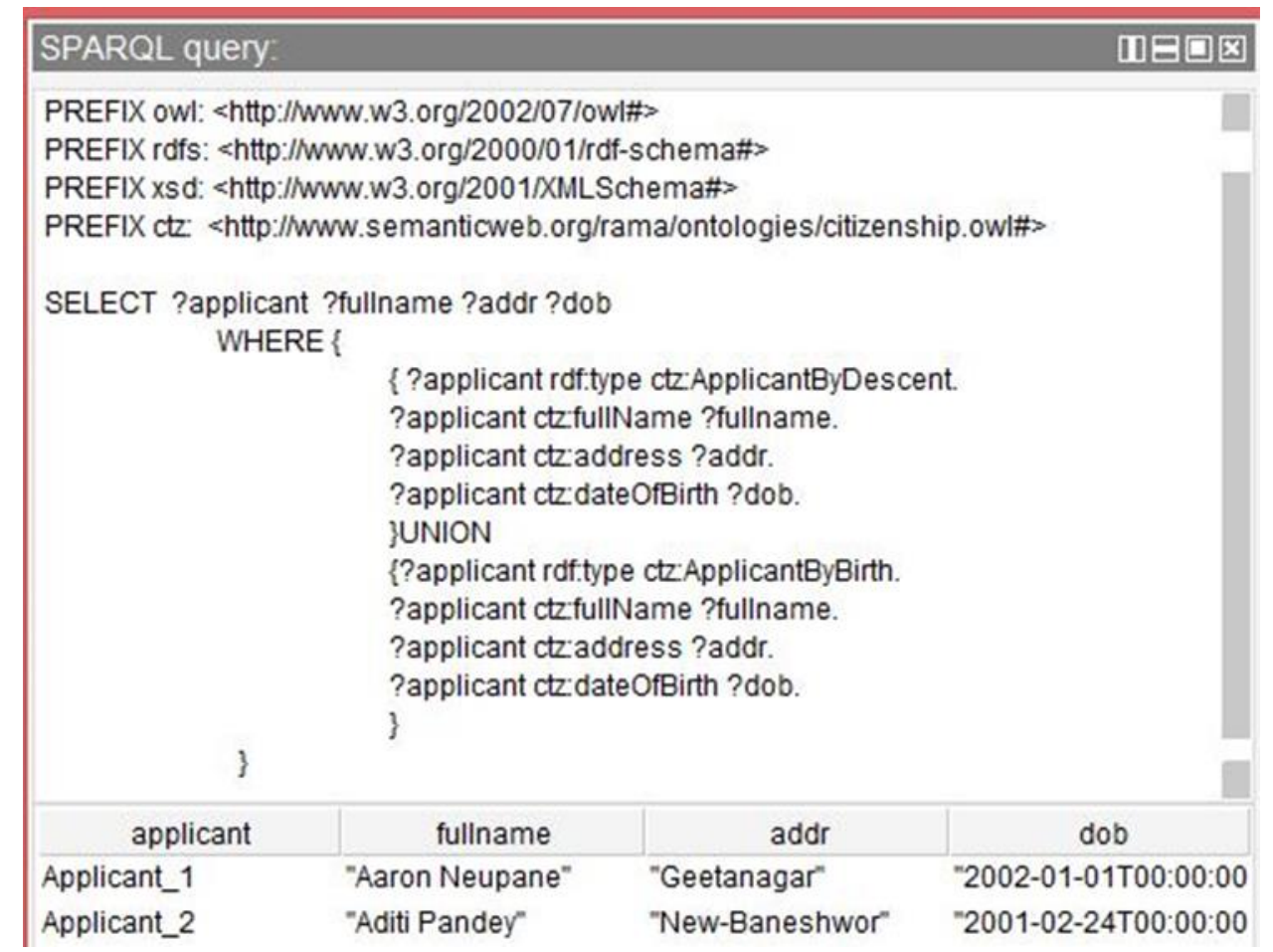

Figure 7: SPARQL Query and Result for Competency Question 9

\section{Conclusion and Further Work}

\subsection{Conclusion}

In this research work, domain ontology for citizenship issuing domain is developed using hybrid methodology. UML from software engineering techniques is used to get conceptual understanding of the domain. OWL is used to represent the ontology due to its expressive power to represent the domain concept. An open source and flexile editor, Protégé is used to develop the ontology. The domain ontology is verified using Protégé inbuilt reasoned HermiT which shows error-free inference for classes, object and data properties. The consistency of the ontology is checked by creating 33 individuals. The validity of the developed ontology is evaluated by answering all the competency questions via SPARQL query.

The work is motivated from the lacking of domain ontology in the field of citizenship which is used as an identity of citizens in almost all of the e-government services of Nepal. The citizenship domain ontology would be valuable addition to the ontology libraries and can be used to achieve interoperability among heterogeneous system through the common representation of the information. 
Journal of Information Technology and Digital World (2020)

Vol.02/ No. 02

Pages: $73-90$

https://www.irojournals.com/itdw/

DOI: https://doi.org/10.36548/jitdw.2020.2.001

The methodology followed to develop the Citizenship Ontology would also be useful in development of ontology in other domain such as Internet of Things, Agriculture, Education.

\subsection{Further Works}

The research project is focused on development and evaluation of citizenship domain ontology. This work includes Acquisition of Nepali Citizenship by Descent and Acquisition of Nepali Citizenship by Birth which can be further extended for other provision of acquisition of Nepali Citizenship as defined in Nepal Citizenship Act 2006 and Nepal Citizenship Rules 2006. Concepts related to revocation and reapplication for certification of citizenship can also be extended.

This research project acquired the domain concept by analyzing Nepal Citizenship Act 2006, Nepal Citizenship Rules 2006, related documents and discussion with domain expert of the field. This work can further be extended by using collaborative knowledge of the existing ontology wherever applicable such as person ontology, family ontology.

\section{References}

[1] G. Antoniou and F. Van Harmelen, A Semantic Web Primer, Second. The MIT Press, 2008 .

[2] R. Garcia-Castro and A. Gomez-Perez, "Interoperability results for Semantic Web technologies using OWL as the interchange language," J. Web Semant., vol. 8, no. 4, pp. 278-291, 2010.

[3] N. F. Noy and D. L. McGuinness, "Ontology Development 101: A Guide to Creating Your First Ontology," Stanford University, Stanford,CA, 94305, 2000. [Online]. Available:

https://protege.stanford.edu/publications/ontology_development/ontology101.pdf.

[Accessed: 10-Nov-2019].

[4] S. Bachhofer et al., "OWL Web Ontology Language Reference," W3C Recommendation, 2004. [Online]. Available: http://www.w3.org/TR/2004/REC-owl-ref-20040210/. [Accessed: 10-Mar-2019].

[5] K. A. Jasmi, B. Basiron, M. Huda, and A. Maseleno, "TACTICAL STEPS FOR EGOVERnMENT DEVELOPMENT," Intnernational J. Pure Appl. Math., vol. 119, no. 
Journal of Information Technology and Digital World (2020)

Vol.02/ No. 02

Pages: 73-90

https://www.irojournals.com/itdw/

DOI: https://doi.org/10.36548/jitdw.2020.2.001

15, pp. 2251-2258, 2018.

[6] T. Cresswell, "Introduction E-government Interoperability , Infrastructure and Architecture : State- of-the-art and Challenges Relating Architecture, Infrastructure and Interoperability," J. Theor. Appl. Electron. Commer. Res., vol. 6, no. 1, 2011.

[7] M. Uschold and M. King, "Towards a Methodology for Building Ontologies conjunction with IJCAI-95 Abstract," in In Proceedings of IJCAI95 Workshop on Basic Ontological Issues in Knowledge Sharing, Montreal, Canada, 1995, no. July, pp. 1-13.

[8] M. S. Rani, S. John, and N. Shah, "Proposal of an Hybrid Methodology For Ontology Development by Extending the Process Models of Software Engineering," Int. J. Inf. Technol. Converg. Serv., vol. 6, no. 1, pp. 37-44, 2016.

[9] G. Brusa, M. L. Caliusco, and O. Chiotti, “A Process for Building a Domain Ontology: an Experience in Developing a Government Budgetary Ontology," in 2nd Australas.Workshop Adv. Ontologies, Hobart, TAS, Australia, 2006, vol. 72, pp. 7-15.

[10] A. A. Alsanad, "A Domain Ontology for Software Requirements Change Management in Global Software Development Environment," IEEE Access, vol. 7, pp. 49352-49361, 2019.

[11] H. Lamharhar, D. Chiadmi, and L. Benhlima, "Ontology-based knowledge representation for e-Government domain," in iiWAS '15: Proceedings of the 17th International Conference on Information Integration and Web-based Applications \& Services, 2015, pp. $1-10$.

[12] A. Ramaprasad, A. S. Ortiz, and T. Syn, "An Ontology of eGovernment," in Proceedings of the 14th IFIP WG 8.5 International Conference on Electronic Government, 2015, no. August, pp. 258-269.

[13] S. Pokharel, M. A. Sherif, and J. Lehmann, "Ontology Based Data Access and Integration for Improving the Effectiveness of Farming in Nepal," in Proc. of the International Conference on Web Intelligence, 2014, no. August.

[14] House of Representatives Nepal 2063, NEPAL CITIZENSHIP ACT 2063 ( 2006 ). Nepal Law Commission, 2006, pp. 1-8.

[15] House of Representatives Nepal 2063, Nepal Citizenship Rules , 2063 ( 2006 ). Nepal Law Commission, 2006.

[16] A. Evans, R. France, K. Lano, and B. Rumpe, "Developing the UML as a Formal Modelling Notation.” Springer Berlin Heidelberg, pp. 336-348, 1999.

[17] Online, "Protege Ontology Library," https://protegewiki. 
Journal of Information Technology and Digital World (2020)

Vol.02/ No. 02

Pages: $73-90$

https://www.irojournals.com/itdw/

DOI: https://doi.org/10.36548/jitdw.2020.2.001

stanford.edu/wiki/Protege_Ontology_Library, 2020.

\section{Authors Biography}

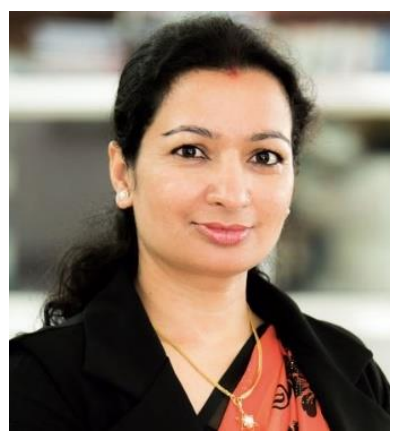

RAMA BASTOLA is pursuing her final semester of M. Phil in ICT at Faculty of Science, Health and Technology, Nepal Open University, Lalitpur Nepal. She has received the Bachelor of Engineering in Computer Engineering from Nepal Engineering College, Pokhara University, Nepal in 2006. She received the Master of Engineeringin Computer Engineering from Nepal College of Information Technology, Pokhara University, Nepal in 2012. She works as Lecturer of Computer Engineering, Department of Electronics and Computer Engineering, Thapathali Campus, Institute of Engineering, Tribhuvan University, Nepal. She has also experiences of software development in various software companies in Nepal. Her areas of research interests include Semantic Web, e-Government System, Natural Language Processing, Neural Network, and Artificial Intelligence.

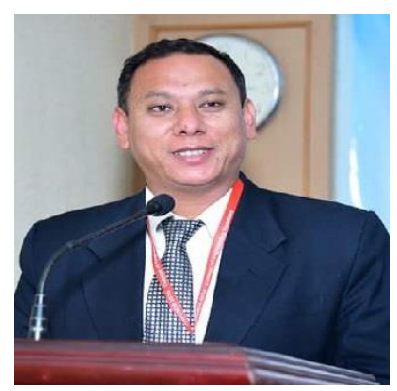

SUBARNA SHAKYA has received the MSc and $\mathrm{PhD}$ degrees in Computer Engineering from the Lviv Polytechnic National University, Ukraine, 1996 and 2000 respectively. He is the Professor of Computer Engineering, Department of Electronics and Computer Engineering, Pulchowk Campus, Institute of Engineering, Pulchowk, Tribhuvan University, Nepal. He has served as Executive Director at National Information Technology Centre, Government of Nepal. His areas of research 
Journal of Information Technology and Digital World (2020)

Vol.02/ No. 02

Pages: $73-90$

https://www.irojournals.com/itdw/

DOI: https://doi.org/10.36548/jitdw.2020.2.001

interests include E-Government system, Computer Systems \&Simulation, Cloud computing\& security, Software Engineering \& Information System, Computer Architecture, Multimedia system.

ISSN: 2582-418X (online)

Information Technology 